Pesq. Vet. Bras. 29(11):881-886, novembro 2009

\title{
Aspectos citológicos e microbiológicos do leite em propriedades no sistema orgânico de produção'
}

\author{
Hélio Langoni $2^{*}$, Débora Tieko Parlato Sakiyama ${ }^{3}$, Felipe de Freitas \\ Guimarães ${ }^{4}$, Benedito Donizete Menozzi ${ }^{5}$ e Rodrigo Costa da Silva ${ }^{6}$
}

\begin{abstract}
Langoni H., Sakiyama D.T.P., Guimarães F.F., Menozzi B.D. \& Silva R.C. 2009. [Cytological and microbiological aspects of milk in farms with an organic system of production.] Aspectos citológicos e microbiológicos do leite em propriedades no sistema orgânico de produção. Pesquisa Veterinária Brasileira 29(11):881-886. Departamento de Higiene Veterinária e Saúde Pública, Faculdade de Medicina Veterinária e Zootecnia, Universidade Estadual Paulista, Campus de Botucatu, Distrito de Rubião Júnior s/n, Botucatu, SP 18618-000. E-mail: hlangoni@fmvz.unesp.br

Nowadays, farmers have great interest in milk production within an organic system due to the consumers' claim for natural products. The purpose of this paper was to study the cytological and microbiological quality of milk produced by four farms in the county of Botucatu, SP, which use organic system management. A total of 150 mammary gland milk samples were tested by CMT and Somatic Cell Count (SCC/mL milk), microbiological examination, and Colony Former Unit Count (CFU mesophile microrganisms/mL milk). From these individual milk samples, $66(44.0 \%)$ were CMT positive. Corynebacterium bovis was isolated from $37.9 \%$ milk samples, Staphylococcus aureus from $18.2 \%$, S. epidermidis from $15.2 \%$, Streptococcus uberis from 3.0\%, and S. dysgalactiae from 3.0\%. Association of at least two different bacteria species was observed in $7.6 \%$ samples. In respect to the whole milk of each farm, the SCC/mL values were in normal limits on three of them (i.e. lower than $400 \times 10^{3}$ ), and considering the $\mathrm{CFU} / \mathrm{mL}$, on three farms high levels were observed $\left(8,5 \times 10^{5} ; 1,5 \times 10^{6} ; 4,1 \times 10^{5}\right)$. From the individual milk samples, contagious mastitis pathogens were isolated predominantly, but environmental microorganisms were detected from the whole milk, as Escherichia coli and Pseudomonas aeruginosa, probably due to contamination during and/or after milking. The results suggest that more than mastitis problems, the four farms studied have hygienic deficiencies, what strengthens the importance of sanitary education to achieve a better milk hygiene quality.
\end{abstract}

INDEX TERMS: Organic milk, cattle, quality, SCC, microbiology, mastitis.

RESUMO.- A produção de leite no sistema orgânico tem despertado o interesse dos produtores rurais, pelo aumento de consumo de produtos naturais. Estudaram-se os

\footnotetext{
${ }^{1}$ Recebido em 14 de julho de 2008.

Aceito para publicação em 9 de junho de 2009.

2 Departamento de Higiene Veterinária e Saúde Pública, Faculdade de Medicina Veterinária e Zootecnia (FMVZ), Universidade Estadual Paulista (Unesp), Distrito de Rubião Jr, Botucatu, SP 18618-000, Brasil. Bolsista pesquisador $1 \mathrm{~A}$ do CNPq. *Autor para correspondência: hlangoni@fmvz.unesp.br

${ }^{3}$ Graduanda em Medicina Veterinária, FMVZ, Unesp-Botucatu, SP.

${ }^{4}$ Mestrando em Saúde Animal, Saúde Pública Veterinária e Segurança Alimentar, FMVZ, Unesp-Botucatu, SP.

${ }^{5}$ Assistente suporte acadêmico II, DHVSP, FMVZ, Unesp-Botucatu, SP.

${ }^{6}$ Doutorando em Saúde Animal, Saúde Pública Veterinária e Segurança Alimentar, FMVZ, Unesp-Botucatu, SP.
}

aspectos citológicos e microbiológicos do leite no sistema orgânico de produção em quatro propriedades no município de Botucatu, SP, utilizando métodos como CMT, exame microbiológico das amostras positivas, contagem de células somáticas (CCS/mL de leite) e Contagem de Unidades Formadoras de Colônias (UFC de microrganismos mesófilos $/ \mathrm{mL}$ de leite) em amostras individuais de leite em animais com pelo menos um teto positivo ao CMT. Foi também realizado a CCS $/ \mathrm{mL}$ de leite e UFC/mL de leite, e exame microbiológico de amostras de leite do conjunto (tanque) de cada propriedade. Das 150 glândulas mamárias examinadas, $66(44,00 \%)$ amostras foram positivas ao CMT, com isolamento de Corynebacterium bovis em $37,90 \%$, Staphylococcus aureus $(18,20 \%)$, S. epidermidis $(15,20 \%)$, Streptococcus uberis $(3,00 \%)$ e $S$. 
dysgalactiae $(3,00 \%)$, e isolamento de mais de um agente bacteriano em $7,60 \%$ das amostras. Os valores de CCS/ $\mathrm{mL}$ das amostras do leite de conjunto estiveram dentro dos limites de normalidade em três das quatro propriedades $\left(<400 \times 10^{3}\right)$, por outro lado considerando a UFC/mL em três das quatro propriedades observou-se altos índices $\left(8,5 \times 10^{5} ; 1,5 \times 10^{6} ; 4,1 \times 10^{5}\right)$. Obteve-se o isolamento de microrganismos ambientais, como Escherichia coli e Pseudomonas aeruginosa, sugerindo a contaminação do leite durante ou após a ordenha, o que reforça a importância de atividades de educação sanitária para obtenção higiênica do leite.

TERMOS DE INDEXAÇÃO: Leite orgânico, bovino, qualidade, CCS, microbiologia, mastite.

\section{INTRODUÇÃO}

A produção de leite orgânico associa baixo custo ao longo do tempo, pois permite independência parcial do produtor em relação aos insumos externos e medicamentos, aumentando a rentabilidade, além de ser um produto interessante para o consumidor, que conhece os benefícios do alimento orgânico, que é biologicamente superior. Este sistema agrega uma série de aspectos positivos em função das práticas que devem ser respeitadas, como por exemplo, a não utilização de antibióticos e pesticidas (Alves 2005).

O mercado de alimentos orgânicos é inovador e, nos países industrializados, pode crescer entre 10\% e 30\% nos próximos anos, segundo relatório da Conferência das Nações Unidas para o Comércio e o Desenvolvimento. Esse nicho cresce em meio à resistência dos consumidores aos transgênicos, sobretudo na Europa, e à preocupação de garantir segurança e qualidade dos alimentos (Aroeira et al. 2005). Segundo Fonseca (2002), na Dinamarca, onde $14 \%$ das vendas totais de leite no país são oriundas de sistemas orgânicos de produção e processamento, há previsão de atingir 100\% do mercado em 2010.

A produção de leite no sistema orgânico não chega a $0,1 \%$ da produção, que é de aproximadamente 25 milhões de litros/ano devido a diversos fatores, como a falta de trabalhos de extensão rural viabilizando o processo para pequenos produtores, a carência de pesquisas científicas adequando a produção animal no sistema orgânico à realidade tropical, além da alimentação, adubação de pastagens, padrões raciais, cuidados sanitários com o rebanho, como controle de endo e ectoparasitos e mastites (Alves 2005). Este sistema associa uma série de aspectos positivos em função das práticas que devem ser respeitadas, que são estabelecidas pela Lei $n^{\circ}$ 10.831, de 23 de dezembro de 2003, regulamentada pelo Decreto no 6.323 , de 27 de dezembro de 2007, que dispõe sobre a agricultura orgânica e dá outras providências (Brasil 2007).

A produção de leite orgânico no Brasil começa a ganhar destaque e suscitar algumas questões importantes sobre a qualidade do produto produzido, como se seus parâmetros estão de acordo com os estabelecidos pelo
Ministério da Agricultura, Pecuária e Abastecimento para o leite fluido e se obedece aos princípios da produção orgânica (Campos 2004).

As bactérias mais comumente associadas à mastite incluem Staphylococcus aureus, estreptococos (S. agalactiae, S. dysgalactiae, S. uberis), coliformes (Escherichia coli, Citrobacter freundii, Enterobacter sp., Klebsiella sp.), Pseudomonas aeruginosa e Arcanobacterium pyogenes (Langoni et al. 1998). Menos comumente, Listeria monocytogenes, Mycoplasma bovis, Mycobacterium bovis, Brucella abortus e Coxiella burnetti (Weimer 1998).

Apesar de alta contagem de células somáticas (CCS) representarem mastite, não consiste em fator de risco para a saúde do consumidor, uma vez que os patógenos são destruídos no processo de pasteurização, exceto toxinas termo-resistentes como algumas produzidas por cepas de $S$. aureus. As enzimas microbianas não são destruídas neste processo e permanecem nos produtos lácteos, diminuindo seu tempo de prateleira (Franco 1996, MagaIhães et al. 2006).

O aumento da demanda por produtos orgânicos e a falta de informações sobre o leite orgânico produzido e comercializado no Brasil contribuíram para que o principal objetivo do presente trabalho fosse avaliar a qualidade microbiológica do leite produzido em sistema orgânico na região de Botucatu, SP.

\section{MATERIAL E MÉTODOS}

Foram utilizadas quatro propriedades certificadas para a produção de leite orgânico, localizadas na região de Botucatu, SP. Procedeu-se a coleta de amostras de leite dos animais em lactação e do leite total produzido antes da entrega ao laticínio, para exame microbiológico de acordo com o NMC (1999), da $\mathrm{CCS} / \mathrm{mL}$ do leite e da contagem de unidades formadoras de colônias (UFC/mL).

O manejo de ordenha apresentava variações entre as propriedades, mas no geral a preparação dos animais incluía estímulo de secreção láctea das vacas utilizando os seus bezerros, lavagem dos tetos com água, ou com uso de pano coletivo, secagem dos tetos com papel toalha, ordenha manual, exceto em uma das propriedades onde a ordenha era mecânica com balde ao pé; não utilização de pré e pós-dipping e soltura do animal ao pasto juntamente com o bezerro ao término da ordenha.

Para a obtenção das amostras de leite, previamente à ordenha, desprezaram-se os primeiros jatos de cada teto, e realizou-se o CMT com classificação dos respectivos quartos mamários em negativo $(-)$, uma $(+)$, duas $(++)$ ou três $(+++)$ cruzes (Schalm \& Noorlander 1957). Em seguida os óstios dos tetos foram higienizados com algodão embebido em álcool iodado $5 \%$, realizando-se coletas de amostras de $10 \mathrm{~mL}$ de leite, em tubos de ensaio estéreis, dos tetos positivos. Nos dias das coletas individuais dos animais, também eram obtidas amostras do leite de conjunto das propriedades, após homogeneização, com utilização de concha esterilizada, para a CCS $/ \mathrm{mL}$ de leite e contagem de UFC de microrganismos mesófilos por $\mathrm{mL}$ de leite e exame microbiológico para caracterização microbiana.

As amostras de leite para os exames microbiológicos foram acondicionadas em caixas de material isotérmico conten- 
do gelo reciclável e encaminhadas ao laboratório do Núcleo de Pesquisas em Mastites (NUPEMAS) do Departamento de Higiene Veterinária e Saúde Pública, Faculdade de Medicina Veterinária e Zootecnia, UNESP, Botucatu, SP. As amostras para contagem de CCS foram armazenadas em tubos plásticos contendo duas pastilhas de bronopol. Para pesquisa da microbiota, as amostras positivas ao CMT, foram cultivadas com auxílio de alça de platina $0,01 \mathrm{~mL}$ de leite em placas de Petri contendo ágar sangue ovino a $5 \%$ e ágar MacConkey. As placas foram incubadas em estufa a $37^{\circ} \mathrm{C}$ com observação do crescimento bacteriano às 24,48 e 72 horas, para verificação dos aspectos morfológicos das colônias, tais como tamanho, pigmentação e presença de hemólise. Os microrganismos isolados foram observados ao microscópio por meio de esfregaços corados pelo método de Gram, e repicados em meio de caldo cérebro-coração para caracterização a partir de provas bioquímicas de acordo com Quinn et al. (2005). Considerou-se como crescimento discreto o isolamento de até nove colônias, moderado entre 10 e 29 colônias, e exuberante com mais de 30 colônias em $0,01 \mathrm{~mL}$ da amostra de leite cultivado em meio de ágar sangue ovino $5 \%$.

Para a análise dos resultados das amostras de leite compostas de cada animal e de cada propriedade foi calculada a mediana dos valores de contagem de UFC $\left(\times 10^{6} / \mathrm{mL}\right)$ e CCS $\left(\mathrm{x} 10^{3} / \mathrm{mL}\right)$.

\section{RESULTADOS E DISCUSSÃO}

Os resultados da CCS $/ \mathrm{mL}$ e UFC/mL das amostras de leite compostas dos animais que revelaram pelo menos um teto positivo ao CMT, podem ser apreciados nos Quadros 1 a 4, da mesma forma que os resultados, do CMT e do exame microbiológico das amostras de leite provenientes de cada teto com mastite subclínica diagnosticada pelo CMT.

O Quadro 5 mostra os resultados em porcentagem do $\mathrm{CMT} /$ tetos e das medianas de CCS/mL e UFC/mL do leite das amostras compostas dos tetos dos animais com pelo menos um quarto mamário positivo ao $\mathrm{CMT}$, de acordo com a propriedade avaliada.

No Quadro 6 podem ser observados os resultados de acordo com cada propriedade para CCS $/ \mathrm{mL}$ e UFC/mL das amostras de leite de conjunto e do exame microbiológico.

Nas amostras individuais, $66(44,0 \%)$ dos quartos mamários apresentaram positividade ao CMT. No exame microbiológico das 66 amostras, 15 (22,7\%) apresentaram resultado negativo sendo as restantes positivas e destas, em 15,2\% foram observados Staphylococcus epidermidis, em 18,2\% S. aureus, em 37,9\% Corynebac-

Quadro 1. Resultados da CCS/mL e UFC/mL das amostras compostas de leite, do CMT dos quartos mamários positivos e de seus respectivos exames microbiológicos da Propriedade 1. Botucatu, 2008

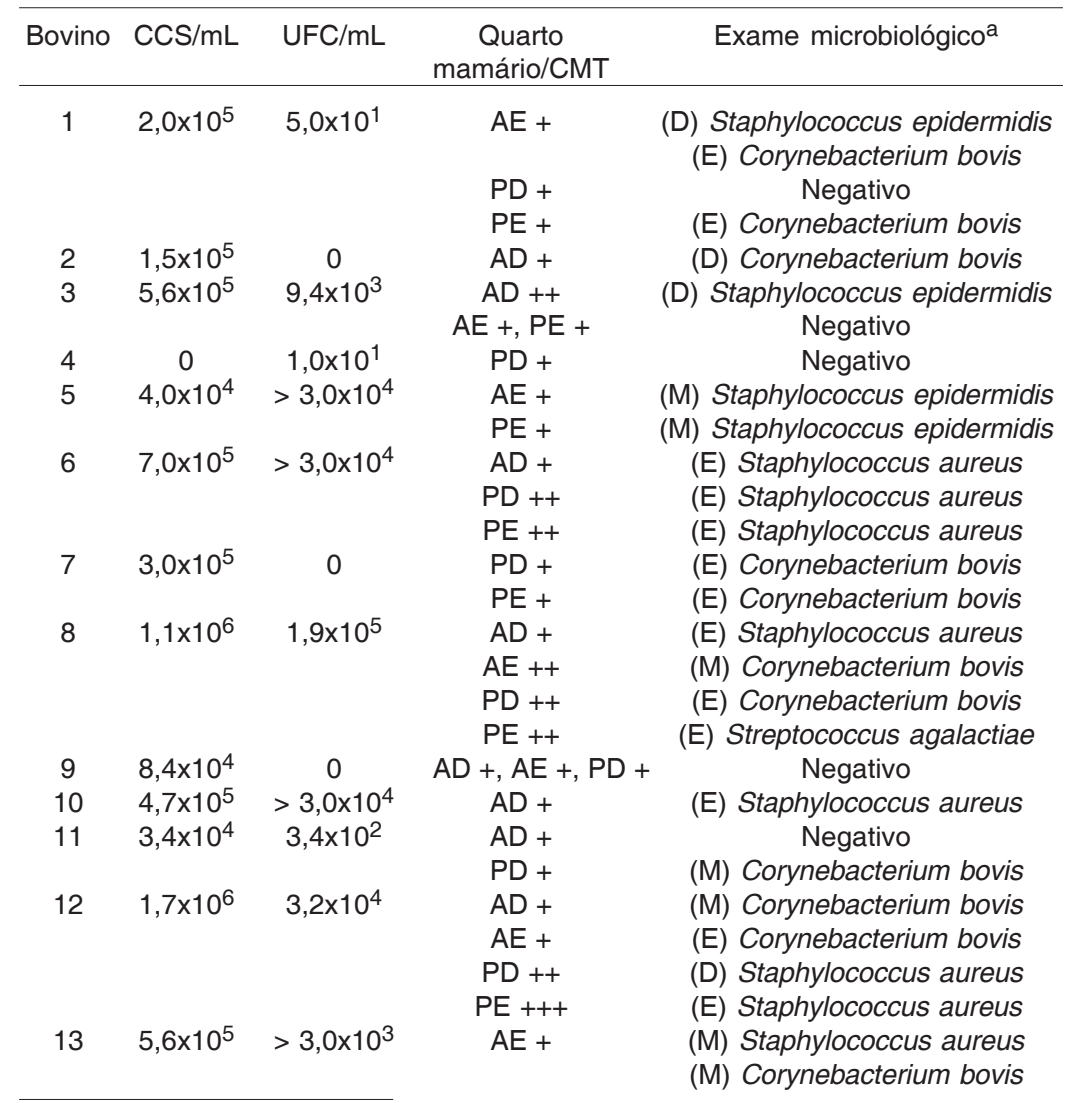

a (D) discreto: 1 - 9 colônias, (M) moderado: 10-29 colônias, (E) exuberante: $\geq 30$ colônias. 
Quadro 2. Resultados da CCS/mL e UFC/mL das amostras compostas de leite, do CMT dos quartos mamários positivos e de seus respectivos exames microbiológicos da Propriedade 2. Botucatu, 2008

\begin{tabular}{ccccc}
\hline Bovino & CCS/mL & UFC/mL & $\begin{array}{c}\text { Quarto } \\
\text { mamário/CMT }\end{array}$ & Exame microbiológico ${ }^{\text {a }}$ \\
\hline 1 & $1,0 \times 10^{3}$ & $1,0 \times 10^{1}$ & $\mathrm{AD}+$ & (M) Corynebacterium bovis \\
2 & $4,4 \times 10^{4}$ & 0 & $\mathrm{PD}++$ & (D) Corynebacterium bovis \\
3 & $3,6 \times 10^{5}$ & 0 & $\mathrm{AE}++$ & (D) Corynebacterium bovis \\
4 & $7,5 \times 10^{4}$ & $3,0 \times 10^{2}$ & $\mathrm{AD}++$ & (M) Staphylococcus epidermidis \\
5 & 0 & Não realizado & Não realizado & Não realizado \\
6 & $5,7 \times 10^{4}$ & $3,0 \times 10^{4}$ & $\mathrm{PD}+$ & (M) Staphylococcus epidermidis \\
7 & 0 & Não realizado & $\mathrm{AE}+$ & Negativo \\
8 & $2,3 \times 10^{6}$ & 0 & $\mathrm{AD}+++$ & Negativo \\
9 & $9 \times 10^{3}$ & Não realizado & Não realizado & (D) Corynebacterium bovis \\
Não realizado
\end{tabular}

Quadro 3. Resultados da CCS/mL e UFC/mL das amostras compostas de leite, do CMT dos quartos mamários positivos e seus respectivos exames microbiológicos da Propriedade 3. Botucatu, 2008

\begin{tabular}{ccccc}
\hline Bovino & $\mathrm{CCS} / \mathrm{mL}$ & $\mathrm{UFC} / \mathrm{mL}$ & $\begin{array}{c}\text { Quarto } \\
\text { mamário/CMT }\end{array}$ & Exame microbiológico ${ }^{2}$ \\
\hline 1 & 0 & $3,9 \times 10^{5}$ & $\mathrm{AD}+$ & (E) Streptococcus uberis \\
& & & $\mathrm{AE}+$ & (D) Corynebacterium bovis \\
Negativo
\end{tabular}

terium bovis, em 3,0\% Streptococcus dysgalactiae e em $3,0 \%$ S. uberis, sendo na maioria das amostras com crescimento exuberante e moderado. Em $7,6 \%$ das amostras houve o isolamento de mais de um agente bacteriano, não se registrando, entretanto, o isolamento de bactérias Gram negativas.

Estes resultados assinalam para uma alta prevalência das mastites subclínicas nas propriedades estudadas de acordo com Fonseca \& Santos (2000) e uma microbiota semelhante àquela observada em vacas no sistema tradicional de produção leiteira, com percentual variável entre as propriedades (Langoni et al. 1998). Segundo Brito et al. (1999), a elevada porcentagem de isolamento de $C$. bovis, sugere que as práticas de desinfecção das tetas por imersão após a ordenha não estão sendo realizadas de maneira efetiva.

No sistema orgânico de produção não há indicação para a utilização de produtos anti-sépticos como pré e pós-dipping, fato que deve contribuir para a ocorrência de infecções intramamárias, principalmente pelos patógenos contagiosos como no presente estudo. $C$. bovis é altamente contagioso, mas as mastites causadas por este agente são quase sempre subclínicas, sendo classificado como um patógeno menor ou secundário (Fonseca \& Santos 2007a). Por outro lado outros autores o consideram relevante na etiologia das mastites (Costa et al. 1995, Langoni et al. 1998), causando redução na produção leiteira. 
Quadro 4. Resultados da CCS/mL e UFC/mL das amostras compostas de leite, do CMT dos quartos mamários positivos e de seus respectivos exames microbiológicos da Propriedade 4. Botucatu, 2008

\begin{tabular}{ccccc}
\hline Bovino & $\mathrm{CCS} / \mathrm{mL}$ & $\mathrm{UFC} / \mathrm{mL}$ & $\begin{array}{c}\text { Quarto } \\
\text { mamário/CMT }\end{array}$ & Exame microbiológico ${ }^{\text {a }}$ \\
\hline 1 & $1,0 \times 10^{3}$ & $(\mathrm{NR})$ & $\mathrm{AD}+$ & (M) Corynebacterium bovis \\
2 & 0 & $3,0 \times 10^{2}$ & $\mathrm{PE}++$ & (M) Staphylococcus epidermidis \\
3 & 0 & $1,0 \times 10^{1}$ & $\mathrm{AE}+$ & (D) Streptococcus dysgalactiae \\
4 & 0 & Não realizado & Não realizado & Não realizado \\
5 & $1,0 \times 10^{3}$ & $3,4 \times 10^{2}$ & $\mathrm{PD}++$ & (M) Corynebacterium bovis \\
6 & $1,2 \times 10^{6}$ & $6,0 \times 10^{3}$ & $\mathrm{AD}+++$ & (M) Staphylococcus aureus \\
7 & $7,6 \times 10^{5}$ & $8,0 \times 10^{3}$ & $\mathrm{PD}+$ & Negativo \\
& & & $\mathrm{PD}++$ & (M) Staphylococcus epidermidis \\
& & & $\mathrm{PE}++$ & (M) Staphylococcus epidermidis
\end{tabular}

a (D) discreto: 1 - 9 colônias, (M) moderado: 10-29 colônias, (E) exuberante: $\geq 30$ colônias.

Quadro 5. Resultados em porcentagens do CMT dos tetos e das medianas de $\mathrm{CCS} / \mathrm{mL}$ e UFC/mL das amostras de leite compostas dos animais com pelo menos um teto positivo ao CMT, de acordo com cada Propriedade. Botucatu, 2008

\begin{tabular}{ccccc}
\hline \multirow{2}{*}{ Propriedade } & $\begin{array}{c}\text { Bovinos/ } \\
\text { quartos }\end{array}$ & $\begin{array}{c}\text { CMT(N) } \\
\text { /quarto(\%) }\end{array}$ & \multicolumn{2}{c}{ Mediana } \\
\cline { 4 - 5 } & $13 / 50$ & $30 / 50,00$ & $3,0 \times 10^{5}$ & $9,4 \times 10^{3}$ \\
1 & $9 / 36$ & $9 / 25,00$ & $4,4 \times 10^{4}$ & $5,0 \times 10^{0}$ \\
2 & $10 / 31$ & $18 / 47,40$ & $6,0 \times 10^{4}$ & $4,1 \times 10^{3}$ \\
3 & $7 / 26$ & $9 / 34,60$ & $1,0 \times 10^{3}$ & $3,4 \times 10^{2}$ \\
4 & $39 / 150$ & $66 / 44,00$ & $7,5 \times 10^{4}$ & $6,85 \times 10^{2}$ \\
Total & & & &
\end{tabular}

Quadro 6. Resultados da CCS/mL e UFC/mL do leite e exame microbiológico das amostras de leite do conjunto de cada propriedade. Botucatu, 2008

\begin{tabular}{cccc}
\hline Propriedade & $\mathrm{CCS} / \mathrm{mL}$ & $\mathrm{UFC} / \mathrm{mL}$ & Exame microbiológico $^{\mathrm{a}}$ \\
\hline 1 & $516 \times 10^{3}$ & $8,5 \times 10^{5}$ & $\begin{array}{c}\text { (E) Escherichia coli } \\
\text { (E) Pseudomonas aeruginosa }\end{array}$ \\
2 & $131 \times 10^{3}$ & $>3,0 \times 10^{3}$ & (D) Staphylococcus epidermidis \\
3 & $353 \times 10^{3}$ & $1,5 \times 10^{6}$ & $\begin{array}{c}\text { (E) Escherichia coli } \\
\text { (E) Streptococcus uberis }\end{array}$ \\
4 & $8 \times 10^{3}$ & $4,1 \times 10^{5}$ & $\begin{array}{c}\text { (E) Escherichia coli } \\
\text { (E) Staphylococcus epidermidis }\end{array}$ \\
& & & (E) Streptococcus dysgalactiae
\end{tabular}

a (D) discreto: 1 - 9 colônias, (M) moderado: 10-29 colônias, (E) exuberante: $\geq 30$ colônias.

No exame microbiológico das amostras dos latões (de conjunto), todas foram positivas e verificou-se a presença de Escherichia coli em três propriedades, de S. epidermidis em duas, de Streptococcus sp. em duas de Bacillus sp. em uma e de Pseudomonas aeruginosa em uma sendo que em apenas uma propriedade isolou-se uma única espécie bacteriana (Quadro 6). Este resultado revela alto grau de contaminação do leite, durante ou pós ordenha, pois não foram isolados microrganismos Gram negativos como coliformes, entre outros, nas amostras de leite provenientes dos tetos com mastite subclínica.

A maioria dos microrganismos Gram-negativos presentes no leite pertence à família Enterobacteriaceae, com predomínio dos coliformes (por exemplo, E. coli, Enterobacter aerogenes, Citrobacter sp. e Klebsiella pneumoni$a e)$. Além de indicadores de falta de higiene na ordenha, bactérias coliformes também têm sido associadas a vários problemas de qualidade dos produtos lácteos, incluindo o desenvolvimento de flavors indesejáveis e produção precoce de gás em queijos (Ryser 1998), fato que diminui o rendimento da produção de derivados lácteos além de reduzir o tempo de prateleira do produto.

As espécies de coliformes habitam naturalmente o trato gastrintestinal dos animais e estão presentes no solo. Apresentam grande capacidade de multiplicação e manutenção nesses locais, aumentando os riscos de mastite ambiental (Fonseca \& Santos 2007b), além da possibilidade de contaminação do leite durante e após o processo de ordenha, o que provavelmente ocorreu nas propriedades estudadas, considerando-se os aspectos higiênicos adotados e os resultados microbiológicos das amostras de leite individuais dos animais, em cada propriedade. Este fato assinala a necessidade de um trabalho de educação sanitária sobre a obtenção higiênica do leite nas propriedades estudadas, com a realização de oficinas para orientação dos envolvidos no manejo dos animais e ordenha. Como continuidade pretende-se a elaboração de cartilha ilustrativa, com linguagem acessível à realidade dos ordenhadores atuantes no manejo das propriedades rurais, especialmente para os casos de produção orgânica e agricultura familiar.

Observa-se no Brasil, diferente de outros países, que a maioria das propriedades do sistema de produção orgânica que migraram para este sistema há pouco tempo são propriedades menores e que necessitam de orientação técnica, apesar de terem sido certificadas para a produção de leite neste sistema. Independentemente do tamanho do rebanho e do tipo de sistema adotado são fundamentais boas práticas de manejo de ordenha para a qualidade microbiológica do leite. A correta higienização do ambiente, das mãos do ordenhador, dos utensílios e equipamentos utilizados durante a ordenha, uso de água de qualidade e produtos adequados para a limpeza e re- 
alização de pré e pós-dipping, utilizando-se como alternativa produtos bioterápicos.

Nas propriedades, de produção orgânica, avaliadas no presente trabalho não eram realizadas as práticas de pré e pós-dipping, o que favorece a ocorrência de $C$. bovis, $S$. epidermidis e $S$. aureus, patógenos contagiosos de mastite, por outro lado, as falhas na higienização de utensílios e equipamentos de ordenha justificam a ocorrência de $\mathrm{CFU} / \mathrm{mL}$ alta no leite total entregue no laticínio. No entanto, o manejo de ordenha deficiente não está correlacionado às normas de produção do sistema orgânico, pois de acordo a Instrução Normativa no 64, de 18 de dezembro de 2008, que aprovou o regulamento técnico para os sistemas orgânicos de produção animal e vegetal, "a produção animal orgânica deve manter a higiene e saúde em todo o processo criatório, obedecendo à legislação sanitária vigente para a produção de leite e adotando o uso de produtos e medicamentos permitidos na prevenção e tratamento de enfermidades dos animais orgânicos como, por exemplo, detergentes neutros e biodegradáveis e fitoterápicos" (Brasil 2008). Portanto, para melhorar as condições higiênicas do leite das fazendas estudadas deveriam ser implementadas nestas, medidas de antisepsia das glândulas mamárias e desinfecção de fômites e equipamentos, com os detergentes neutros, biodegradáveis e fitoterápicos autorizados pela Normativa 64/2008.

\section{CONCLUSÕES}

O predominante isolamento de patógenos contagiosos como Corynebacterium bovis, Staphylococcus aureus e $S$. epidermidis das amostras individuais, associado ao fato da $\mathrm{CCS} / \mathrm{mL}$, indicadora do nível de mastite, estar dentro do limite de normalidade na grande maioria das amostras individuais, bem como, no leite do conjunto, permite concluir não ser a mastite um problema.

$\mathrm{O}$ isolamento dos patógenos contagiosos deve estar relacionado à deficiência no manejo durante a ordenha, podendo ser corrigido pela utilização de medidas preventivas como pré e pós-dipping.

A predominância de patógenos ambientais como Escherichia coli e Pseudomonas aeruginosa, nas amostras de leite dos latões destas propriedades, entregues no laticínio, indica a ocorrência da contaminação no leite durante e/ou após a ordenha. Estes resultados demonstram a importância da educação sanitária para a obtenção higiênica do leite.

Agradecimentos.- À pós-graduanda Deolinda Maria Vieira Filha Carneiro pelo auxílio em parte das coletas.

\section{REFERÊNCIAS}

Alves A.A. 2005. Panorama atual da produção orgânica de leite no Brasil. Revta Agroecol. Hoje 29:24-25.

Aroeira L.J.M., Furlong J., Prata M.C.A.P., Pires M.F.A. \& Morenz M.J.F.
2005. Tecnologias para a produção orgânica de leite. Revta Agroecol. Hoje 29:15-16.

Brasil 2007. Ministério da Agricultura Pecuária e do Abastecimento. Decreto $n^{\circ}$ 6.323, de 27 de Dezembro de 2007. Regulamenta a Lei $n^{\circ}$ 10.831, de 23 de dezembro de 2003, que dispõe sobre a agricultura orgânica, e dá outras providências. Diário Oficial da União de 27 de Dezembro de 2007, Seção 1, página 2, Brasília, DF. Capturado em: 25 jun. 2007. Online. Disponível em: http://www.agricultura.gov.br/

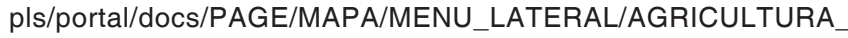
PECUARIA/PRODUTOS_ORGANICOS/AO_LEGISLACAO/DECRETO\%206323. PDF

Brasil 2008. Ministério da Agricultura Pecuária e do Abastecimento. Instrução Normativa no 54 , de 18 de dezembro de 2008. Aprova o Regulamento Técnico para os Sistemas Orgânicos de Produção Animal e Vegetal. Diário Oficial da União de 19 de Dezembro de 2008, Seção 1, Página 21, Brasília, DF. Capturado em: 22 abr. 2009. Online. Disponível em: http://extranet.agricultura.gov.br/sislegis-consulta/ consultarLegislacao. do?operacao=visualizar\&id $=19345$

Brito M.A.V.P., Brito J.R.F., Ribeiro M.T. \& Veiga V.M.O. 1999. Padrão de infecção intramamária em rebanhos leiteiros: exame de todos os quartos mamários das vacas em lactação. Arq. Bras. Vet. Zootec. 51(2):129-135.

Campos E.P.C. 2004. Qualidade microbiológica, físico-química e pesquisa de resíduos de antibióticos e pesticidas no leite bovino produzido pelo sistema convencional e pelo sistema orgânico. Dissertação de Mestrado, Faculdade de Medicina Veterinária e Zootecnia, Unesp, Botucatu. 58p.

Costa E.O., Benites N.R., Melville P.A., Pardo R.B., Ribeiro A.R. \& Watanabe E.T. 1995. Estudo etiológico da mastite clínica bovina. Revta Bras. Med. Vet. 17(4):156-158.

Fonseca M.F.A.C. 2002. Produção orgânica de leite no Brasil, p.93111. In: Ibid. (Ed.), Cenário da Produção e da Comercialização dos Alimentos Orgânicos. Embrapa Gado de Leite, Juiz de Fora.

Fonseca L.F.L. \& Santos M.V. 2000. Qualidade do leite e controle de mastite. Lemos Editorial, São Paulo.

Fonseca L.F.L. \& Santos M.V. 2007a. Estratégias para Controle de Mastite e Melhoria da Qualidade do Leite. Manole, Barueri, São Paulo. 4p.

Fonseca L.F.L. \& Santos M.V. 2007b. Situação atual da cadeia produtiva leiteira do Brasil. 4º Encontro Pesq. Mastites, Botucatu, p.18-29.

Franco B.D.G.M. 1996. Fatores intrínsecos e extrínsecos que controlam o desenvolvimento microbiano nos alimentos, p.13-26. In: Franco B.D.G.M. \& Landgraf M. (Eds), Microbiologia dos Alimentos. Atheneu, São Paulo.

Langoni H., Da Silva A.V., Cabral K.G. \& Domingues P.F. 1998. Aspectos etiológicos na mastite bovina: flora bacteriana aeróbica. Revta Bras. Med. Vet. 20(5):204-209.

Magalhães H.R., Faro L.E., Cardoso V.L., Paz C.C.P., Cassoli L.D. \& Machado P.F. 2006. Influência de fatores de ambiente sobre a contagem de células somáticas e sua relação com perdas na produção de leite de vacas da raça holandesa. Revta Bras. Zootec. 35:415-421.

Quinn P.J., Markey B.K. Carter M.E., Donnelly W.J. \& Leonard E.C. 2005. Microbiologia Veterinária e Doenças Infecciosas. Editora Artmed, Porto Alegre. 512p.

Ryser E.T. 1998. Microorganisms of importance in raw milk. Mem. Congr. Panam. Control Mastitis Calidad Leche, Mérida, p.236-239.

Schalm O.W. \& Noorlander D.O. 1957. Experiments and observations leading to development of the California Mastitis Test. J. Am. Vet. Med. Assoc. 130:199-207.

Weimer P.J. 1998. Microbiology of the dairy animal, p.1-54. In: Marth E.H. \& Steele J.L. (Eds), Applied Dairy Microbiology. Marcel Dekker, New York. 